\title{
Scale up of a Low Energy Process for the Production of Oil in Water Emulsions
}

\author{
By Sara Raposo* \\ Manuela Urbano ${ }^{\dagger}$ \\ Helena Ribeiro
}

Consistent with the technological advancements during the past 1015 years, numerous formulations and drug delivery concepts emerged for enhanced therapeutic applications. Because these formulations are relatively new, the industry needs to address several challenges, in this sense cold processed emulsions can be used. The aim of the present work is to study the risk associated to the scale transposition of a cold processed oil in water emulsion and access the production costs savings associated to this new process.

The lab scale of the emulsion was developed by the preparation of the oil liquid phase (19\%) at room temperature. The aqueous phase was prepared also at room temperature by dispersing the aqueous thickening agents in water, after the cetrimide $(0.075 \% \mathrm{w} / \mathrm{w})$ and the pentanediol $(10 \% \mathrm{w} / \mathrm{w})$ were added to the aqueous solution and the resulting mixture was homogenized until a clear homogeneous gel was achieved. The emulsification phase was performed at room temperature by slowly adding the oil phase to the aqueous phase with high shear mixing at a rate about $12800 \mathrm{rpm} / \mathrm{min}$ (IKA® T25 Ultra Turrax). Two scales up were performed using the same methodology: ten-fold increase - pilot lab-scale (IKA® LR $2 S T)$ and a 100 fold increase - pilot industrial-scale (Dumek® Dumoturbo 25). The three scales were compared in terms of droplet size distribution measured by light scattering and the rheological profiles. The total production costs, for the cold process compared with a conventional hot process, were calculated taking into account the electrical and water costs. The results showed that the droplet size of the emulsion significantly decreased when the production scale was increased $(23.23 \pm 3.89 \mu \mathrm{m} ; 18.42 \pm 5.76 \mu \mathrm{m}$ and $6.37 \pm 2.49 \mu \mathrm{m}$, for lab, pilot-lab and pilot-industrial scale, respectively). Moreover, the industrial pilot-scale produced an emulsion with a monomodal population. The apparent viscosity values are in accordance with the latter results. The emulsion produced in the industrial pilot-scale seemed to be more structured. In conclusion the scale-up process led

\footnotetext{
*Researcher, Laboratório Edol, Produtos Farmacêuticos, S.A., Portugal.

${ }^{\dagger}$ Technical and Production Manager, Laboratório Edol, Produtos Farmacêuticos, S.A., Portugal.

*Associate Professor, University of Lisbon, Portugal.
} 
Vol. 2, No. 1 Raposo et al.: Scale up of a Low Energy Process for the Production...

to more significant alterations on the rheological profile and on the droplet size distribution of the placebo produced by the industrialscale than the lab-scale production. This cold process allowed a total production savings of more than $17 \%$ when compared to the traditional hot process.

\section{Introduction}

According to the report of a conference organized by the Board of Pharmaceutical Sciences of the International Pharmaceutical Federation (Shah et al., 2010) concerning the pharmaceutical sciences in 2020, the 'blockbuster' model is unlikely to be sustainable as increased $R \& D$ costs are coupled with a disproportionately lower financial yield from new pharmaceutical products. There is a need to change some drive forces that might determine how the pharmaceutical sciences will look in 2020, especially the efficiency of the manufacturing processes allowing the provision of cheaper development costs.

Regarding this scenario, the benefits of cold process emulsions are many and varied.

The structure of emulsions containing non ionic surfactants, prepared by the cold process emulsification, is easier to control. The benefits of cold processed emulsions are not limited to the ease of structure control, but they also allow a decrease in the production costs. As they are easier to process, due to the elimination of the heating and cooling down phases, the time of production can be decreased, increasing production capacity as well as decreasing the energy and water consumptions. Kurt, 2009, showed that the cold process emulsification saves, on average, more than $75 \%$ of the energy compared to a hot process, as well as saves a significant amount of time. This process has also environmental advantages, as the use of less energy means lower emissions of $\mathrm{CO}_{2}$.

However, only a limited number of excipients can be used in such emulsions. They need to be either liquids, or readily soluble in the oil and water phases. Wax-like materials commonly used in dermatological emulsions which need to be melted, such as cetostearyl alcohol, cannot be used.

Introducing a pharmaceutical product on the market involves several stages of research. During the development stage, a series of refinements in the formulation is achieved progressively, including the optimization of the manufacturing processes. The scale-up stage comprises the integration of the previous phases of development, as well as the transfer of technology to fabricate a given product.

This stage is extremely important since many process limitations arise, which were not detectable on the small scale, and become significant on the transposition to a larger scale. In practice, the transition from a laboratory production system to an industrial production is not direct, and the product is usually manufactured on intermediate scales, larger than the initial ones, but smaller than the industrial scale. 
Basically, the idea is to simulate production as much as possible and to optimize the operating parameters before a large-volume work is performed. A scale-up procedure based on a well design and prepared technical transfer will assure the quality of the product, an overall economy of resources and a timely and readiness achievement of the markets (Galindo-Rodríguez et al., 2005; Baby et al., 2008).

The role of the pilot scale batches is to provide predictive data of the production scale product. It may be necessary to further develop and optimize the manufacturing process using several pilot scale batches. The pilot batch therefore provides the link between the process development and the industrial production of the final product.

The purpose of the pilot batch is to challenge the method proposed for routine production, identifying and analyzing the difficulties and the critical points of the manufacturing process. The pilot batch size should correspond to, at least, $10 \%$ of the production scale batch, that is such that the multiplication factor for the scale-up does not exceed 10 (CPMP, 2001).

\section{Materials and Methods}

\section{Materials}

Ethoxydiglycol (Transcutol ${ }^{\circledR} \mathrm{CG}$ ), was a kind gift from Gattefossé (France); 2-methyl-2,4-pentanediol (99\% grade) (pentanediol), and hydroxypropylmethylcellulose (HPMC) were obtained from Sigma Aldrich, (Germany); Bis-PEG/PPG-16/16 PEG/PPG-16/16 dimethicone and caprylic/ capric triglyceride (Abil ${ }^{\circledR}$ Care 85), , C12-15 alkyl benzoate (Tegosoft ${ }^{\circledR} \mathrm{TN}$ ), PEG-20 glyceryl laurate (Tagat ${ }^{\circledR} \mathrm{L} 2$ ), and cetrimide BP were a kind gift from Evonik Industries AG (Germany). Methyl vinyl ether/maleic anhydride copolymer crosslinked with decadiene (PVM/MA) (Stabileze $\left.{ }^{\circledR} \mathrm{QM}\right)$ was a gift from ISP (EUA). Isopropyl myristate (IPM), was obtained from José Vaz Pereira, S.A., (Portugal). Purified water was obtained by reverse osmosis (Millipore, Elix® 3).

\section{Methods}

$\underline{\text { Lab-Scale }}$

The lab scale of the cold processed emulsion was developed by the preparation at room temperature of an oil liquid phase, achieved by dissolving the bis-PEG/PPG-16/16 PEG/PPG-16/16 dimethicone (and) caprylic/capric triglyceride $(5 \% \mathrm{w} / \mathrm{w})$ and the co-emulsifier (PEG-20 glyceryl laurate, $4 \%$ $\mathrm{w} / \mathrm{w})$ into the oils (C12-15 alkyl benzoate, $5 \% \mathrm{w} / \mathrm{w}$ and isopropyl myristate, $5 \% \mathrm{w} / \mathrm{w})$ and mixing (Helipath ${ }^{\circledR} 130 \mathrm{rpm}$ ) at room temperature for about 30 minutes. Next, an aqueous phase was prepared at room temperature by dispersing the aqueous thickening agents (HPMC, 2\% w/w and PVM/MA, $0.3 \% \mathrm{w} / \mathrm{w})$ in water. The cetrimide at $0.075 \% \mathrm{w} / \mathrm{w}$ and the pentanediol $(10 \%$ w/w) were added to the aqueous solution and the resulting mixture was homogenized until a clear homogeneous gel was achieved. The emulsification 
phase was performed at room temperature by slowly adding the oil phase to the aqueous phase with high shear mixing at a rate about $12800 \mathrm{rpm} / \mathrm{min}\left(\mathrm{IKA}^{\circledR}\right.$ T25 Ultra Turrax).

\section{Pilot Lab-Scale Production}

The scale-up production of the emulsion A was carried out by increasing in ten-fold the volume of the lab scale using a miniplant reactor system (IKA ${ }^{\circledR}$ LR 2 ST).

Pilot Industrial-Scale Production

A batch of $15 \mathrm{~kg}$ of placebo A was produced in a Dumek ${ }^{\circledR}$ Dumoturbo 25.

Figure 1. Flow Chart of the Placebo A-Industrial Scale Production

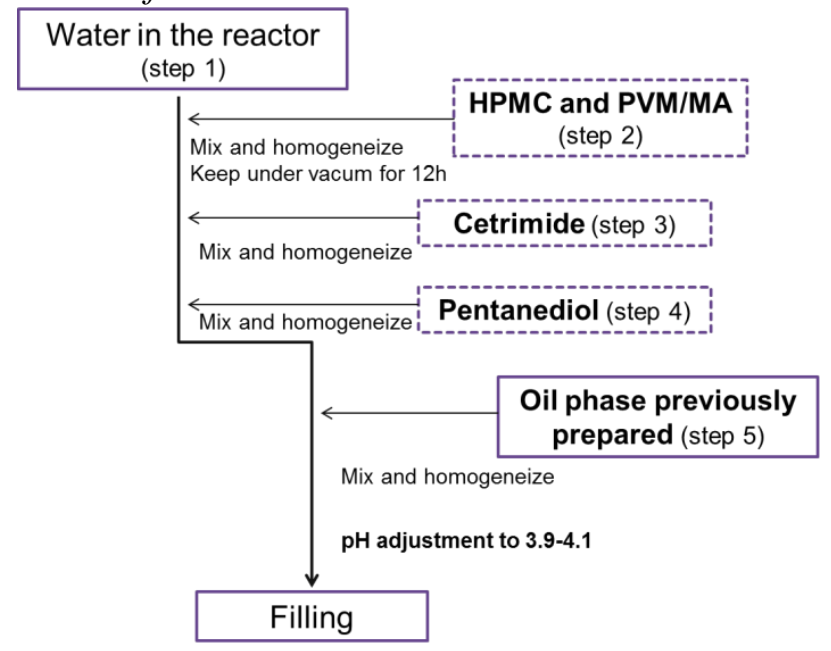

In-Process Tests in Pilot Industrial-Scale Production

The $\mathrm{pH}$ of the placebo, during the industrial-scale production, was measured using a pH meter (Metrohm ${ }^{\circledR} \mathrm{pH}$ Meter 744$)$, with a glass electrode.

\section{Droplet Size Analysis}

The size distribution of the droplets of the three samples of placebo, produced by the three different scales was measured by light scattering using a Malvern Mastersizer ${ }^{\circledR} 2000$ (Malvern Instruments, Worcestershire, UK) coupled with a Hydro S accessory. For a correct turbidity, about $0.5 \mathrm{~g}$ of each corresponding to an obscuration between $25 \%$ and $28 \%$, was added in the sample chamber containing $150 \mathrm{ml}$ of water using a stirrer at $700 \mathrm{rpm}$. Data are expressed in terms of relative distribution of volume of particles in the range of size classes (results displayed as mean $\pm \mathrm{SD} ; \mathrm{n}=5$ ).

\section{Flow Curves}

Rheograms were determined using a Brookfield ${ }^{\circledR}$ viscometer, model RV DV II, at $22{ }^{\circ} \mathrm{C}$. A sample, of each scale, was placed into an appropriate container and the rheograms were obtained by submitting the samples to growing shear rates (from 0.6 to $122 \mathrm{~s}^{-1}$ ) during $30 \mathrm{~s}$ at each shear rate value. 
Spindle SC4-27 was used for each sample. The samples were analyzed 1 month after production.

Comparison between Cold and Hot Processes concerning the Production Costs

The manufacturing process (cold process) was compared with a conventional hot process, considering that after the introduction of the water phase the reactor is heated to $80^{\circ} \mathrm{C}$; afterwards, the oil phase is heated to $80{ }^{\circ} \mathrm{C}$ prior to the introduction in the reactor and, after the homogenization of both phases, the reactor is programmed to decrease the temperature to $25^{\circ} \mathrm{C}$ which takes approximately $1 \mathrm{~h}$ considering $15 \mathrm{~kg}$ of product. The total production costs were calculated taking into account the electrical and water expenditures.

\section{Results}

\section{In-Process Tests in Pilot Industrial-Scale Production}

The $\mathrm{pH}$ is a critical parameter since MF presents its maximum stability below pH 4 (Teng et al., 2003). Thus, it is critical to assess the $\mathrm{pH}$ during the production to avoid drug instability. According to Table 1 , the $\mathrm{pH}$ of the water was within the specifications (5.0-7.0). However, after the inclusion of both polymers (HPMC and PVM/MA) and cetrimide the $\mathrm{pH}$ drastically decreased. In step 4, which was the phase where MF was added dispersed in the glycol, the $\mathrm{pH}$ was acidic. Thus, the degradation of the drug is not expected during the production process. At the end of the process the $\mathrm{pH}$ was adjusted with $\mathrm{NaOH}$ to 4 to avoid emulsion instability that can occur at low $\mathrm{pH}$ values.

Table 1. $p H$ Values in Process Control for Placebo A during the Industrial Pilot Scale Production

\begin{tabular}{|c|c|}
\hline Step & $\mathrm{pH}$ values \\
\hline 1 & 5.30 \\
\hline 2 & 2.72 \\
\hline 3 & 2.04 \\
\hline 4 & 2.12 \\
\hline 5 & 2.72 \\
\hline
\end{tabular}

Droplet Size Analysis

The production scale influences the droplet size distribution. In the two lab scales (lab- scale and pilot lab-scale), the placebo A presented a bimodal population whereas after the industrial pilot-scale production, the placebo A presented a monomodal population (Figure 2). The mean droplet size (90\% of the droplets) for the two lab scales, immediately after preparation, was similar $(23.23 \pm 3.89 \mu \mathrm{m}$ and $18.42 \pm 5.76 \mu \mathrm{m}$, for lab scale and pilot-lab scale, respectively). The mean droplet size ( $90 \%$ of the droplets) for pilot-industrial scale presented a smaller mean droplet size dispersion $(6.37 \pm 2.49 \mu \mathrm{m})$. 
Figure 2. Droplet Size Distribution of Lab-Scale (Red Line), Pilot Lab-Scale (Green Line) and Industrial Pilot-Scale (Blue Line) Batches, Stored at $25{ }^{\circ} \mathrm{C}$ and 1 Month after Production

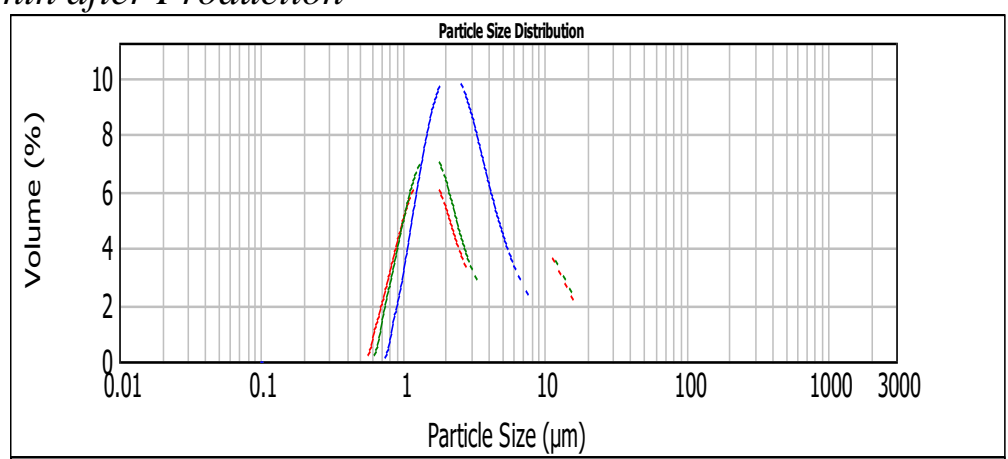

\section{Flow Curves}

Representative flow curves are shown in Figure 3 with apparent viscosity values calculated at the apex of the loop (Table 2). The results show that the apparent viscosity decreases concomitantly with the increase of the shear rate in the three scales.

Figure 3. Flow Curves. Shear Stress as Function of Shear Rate of Lab-Scale (Grey Line), Pilot Lab-Scale (Dashed Line) and Pilot Industrial-Scale (Black Line)

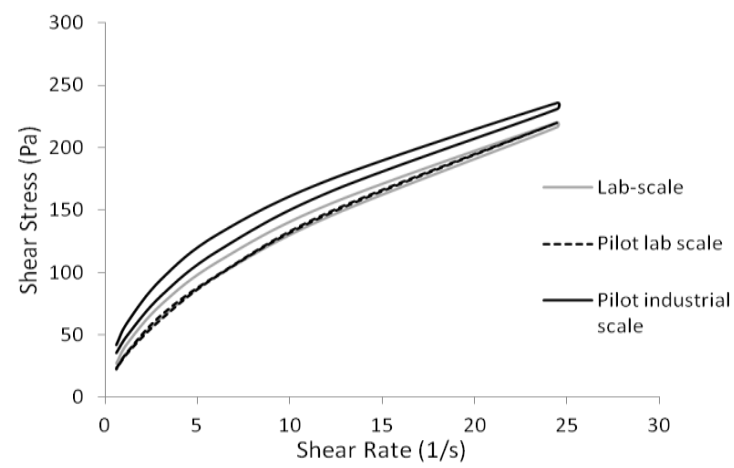

The apparent viscosity values provide a comparison of the resistance to structural breakdown between the emulsions, and the loop areas compare the amount of structure that fractures in the standardized cycle. As we increase the production scale, the resistance to the structural breakdown slightly increases. The emulsion produced in pilot industrial-scale presented the highest value of apparent viscosity at the apex of the loop.

Table 2. Apparent Viscosity Values Calculated at the Apex of the Loops $\left(24.47 \mathrm{~s}^{-1}\right)$

\begin{tabular}{|c|c|}
\hline & Apparent viscosity at $24.47 \mathrm{~s}^{-1}$ \\
\hline Lab - scale & 8.85 \\
\hline Pilot lab - scale & 9.00 \\
\hline Pilot industrial - scale & 9.65 \\
\hline
\end{tabular}


Comparison between Cold and Hot Processes concerning the Production Costs

In the lab-scale the emulsification was achieved by high shear homogenization during $5 \mathrm{~min}$ at room temperature. In processing $15 \mathrm{~kg}$, it was found that the combination of a lower shear and a longer time of homogenization were the most suitable conditions for the emulsification phase. However, at the end of the process, it was observed that the temperature in the reactor increased to $43{ }^{\circ} \mathrm{C}$, thus the refrigerator system was needed. According to Table 3 , despite the energy produced by the high shear of homogenization, the water and energy consumption were decreased in 36.7 and $67.0 \%$, respectively, compared to a conventional hot process. The cold process method used in the preparation of the emulsion allowed a decrease in the total production costs of more than $17 \%$. This value is obtained taking into account the differences in the total production costs between the two processes. These differences arise from the equipment costs per hour in terms of water and electrical costs (Table 3), reactor amortization, equipment availability and human resources costs per hour. As the production is faster, the costs related to human resources are lower, the amortization of the equipment decreases and the availability increases as more batches are produced. Other factors such as costs related to the raw materials, packaging, quality control (in process and final product), validation methods and inspections are similar between the two processes.

Table 3. Comparison between the Cold and Hot Processes in Terms of Production Costs for Placebo A

\begin{tabular}{|c|c|c|c|}
\hline & $\begin{array}{c}\text { Electrical costs } \\
(€ / \text { uni })\end{array}$ & $\begin{array}{c}\text { Water costs } \\
(€ / \text { uni })\end{array}$ & $\begin{array}{c}\text { Total production } \\
(€ / \text { uni })\end{array}$ \\
\hline Cold process & 0.001 & 0.002 & 0.58 \\
\hline Hot process & 0.003 & 0.003 & 0.70 \\
\hline Savings $(\%)$ & 67.0 & 36.7 & 17.1 \\
\hline
\end{tabular}

\section{Discussion}

It is known that problems associated with costs and time consuming of industrial processes may be avoided if key parameters are previously studied. Industrial processes are usually designed through a gradual increase of the manufactured batch size. The processing conditions required to produce a high quality product with the desire characteristics vary according to the type of ingredients used and the manufacture conditions.

It is known (Eccleston, 2010) that for emulsions structured by fatty alcohol/non-ionic surfactants, the key points are the cooling rate and the extent of mixing step. As cold processed conditions were used, the extent of the mixing step is the crucial point. Polymers, such as HPMC, need relatively mild conditions of temperature and agitation to prevent depolymerization, whereas, surfactant and fatty alcohol blends need to be processed under high shear. That is the reason that firstly the preparation is submitted at a lower shear to disperse 
the polymers and, after the addition of the oil phase containing the non ionic surfactants, under a high shear.

The in-process tests, as presented in the guideline ICH Q6A (ICH, 1999), must be performed during the manufacture of the drug product, rather than as part of the formal battery of tests, which are conducted prior to release.

The $\mathrm{pH}$ determination during processing had the objective to identify and optimize the operating parameters since it is a critical point to the drug stability. The drastic decrease of the $\mathrm{pH}$ value after the inclusion of both polymers is attributed to the PVM/MA polymer. The monoesters of PVM/MA contain two essential components: a hydrophobic ester group and a solubilizing carboxylic group. Due to the acidic carboxylic groups, the $\mathrm{pH}$ at the surface of the PVM/MA matrix is low, decreasing the bulk pH (Hämäläinen et al., 1998).

The droplet size of the emulsion significantly decreased when the production scale was increased. Moreover, the industrial pilot-scale produced an emulsion with a monomodal population (Figure 2). The apparent viscosity values are in accordance with the latter results. The emulsion produced in the industrial pilot-scale seemed to be more structured. However, it should be taken in account that only one batch was produced. The variations batch to batch that usually occur were not analyzed. Nevertheless, the results suggested that the emulsion produced in industrial pilot-scale had a better physical stability.

These results were related to the type of homogenizer of the different equipments. Geometric similarities of the agitation systems used at lab and pilot-scales for the emulsification step should be maintained at all production scales in order to obtain a similar fluid motion (Zlokarnik, 2001). However, it was not possible to use devices with the same geometry in the three scales. According to the theory of non-dimensional models ( $\Pi$ Theorem VashyBuckingham), two scales may be considered similar if they take place in a completely similar geometric space and all dimensionless numbers necessary to describe them, must have the same numerical value (Buckingham, 1914). For example, Froude number is a dimensionless number that describes the interaction between centrifugal force (pushing the particles against the container wall) and the centripetal force produced by the wall, thereby creating a compression zone. The Froude equation can also be used to calculate the time of emulsification since there geometrical similarity between the containers, the same stirring speed and a linear increase in the batch size (Block, 2001). In this case Froude number could not be applied. In the lab-scale, it was used manual agitation followed by rotor stator homogenization, in the pilot lab-scale the homogenization was achieved using an anchor stirrer and in the pilot industrial-scale a turbine stator and a universal rotor helix shaped. The geometric space as well the dimensions and the rotor speeds were different in all scales. That's why the batches were controlled using droplet size distribution and apparent viscosity as critical quality attributes.

Concerning the batch size of the industrial pilot-scale production, we decided to produce $15 \mathrm{~kg}$ of placebo A because, according to the CPMP/QWP/848/96, the batch size should correspond to, at least, $10 \%$ of the 
production scale batch.

\section{Conclusions}

The scale-up process led to more significant alterations on the rheological profile and on the droplet size distribution of the placebo produced by the industrial-scale than the lab- scale production. Moreover, it was observed that a scale-up procedure must be designed according to a robust technology of technical transfer in order to assure product quality, an overall reduction of the production costs and readiness achievement of the markets. The risks associated to the process of scale-up were minor. The cold process method of production allowed a total savings of more than $17 \%$ when compared to the traditional hot process.

\section{Acknowledgments}

Our thanks to Fundação para a Ciência e Tecnologia (Portugal), FEDER (Doctoral Grant SFRH/BDE/33550/2009), Strategic Project PEstOE/SAU/ UI4013/2011) and Laboratório Edol S.A.

\section{References}

Baby, A.R., Santoro, D., Robles Velasco, M.V., Dos Reis Serra, C.H. Emulsified systems based on glyceryl monostearate and potassium cetylphosphate: Scale-up and characterization of physical properties. Int J Pharm 2008;361:99-103.

Block, L.H. Nonparenteral liquids and semisolids. In: Levin M (ed), Pharmaceutical Process Scale-Up. $3^{\text {rd }}$ Edition, Marcel Dekker, Inc. 2001, pp. 57-94.

Buckingham, E. On physically similar systems: illustrations of the use of dimensional equations. Phys Rev NY 1914; 4:345-376.

CPMP. Notes for guidance on process validation (EMEA/CVMP/598/99/CPMP/ QWP/848/96. Committee for Proprietary Medicinal Products, EMEA, London (UK), 2001.

Eccleston, G. The microstructure and properties of fluid and semisolid lotions and creams. IFSCC Magazine 2010;3-4.

Galindo-Rodríguez, S.A., Puel, F., Briançon, S., et al. Comparative scale-up of three methods for producing ibuprofen-loaded nanoparticles. Eur J Pharm Sci 2005;25: 357-367.

Hämäläinen, K.M., Määttä, E., Piirainen, H., et al. Roles of acid / base nature and molecular weight in drug release from matrices of gelfoam and monoisopropyl ester of poly(vinyl methyl ether-maleic anhydride). J Control Release 1998;56:273-283.

International Conference on Harmonisation (ICH) of Technical Requirement for Registration of Pharmaceuticals for Human Use, Test Procedures and Acceptance Criteria for New Drug Substances and New Drug Products: Chemical Substances, Q6A, ICH, 1999. 
Vol. 2, No. $1 \quad$ Raposo et al.: Scale up of a Low Energy Process for the Production...

Kurth, N. Cold process emulsions with hot performance. Household and Personal Care today. 2009, Mar; 1, 42.

Shah, V., Besancon, L., Stolk, P., et al. The Pharmaceutical Sciences in 2020: Report of a conference organized by the Board of Pharmaceutical Sciences of the International Pharmaceutical Federation (FIP). Pharm Res 2010;27:396-399.

Teng, X., Cutler D, Davies N. Degradation kinetics of mometasone furoate in aqueous systems. Int J Pharm 2003;259:129-141.

Zlokarnik, M. Dimensional analysis and scale-up in theory and industrial application. In: Levin M (ed.), Pharmaceutical Process Scale-Up. $3^{\text {rd }}$ Edition, Marcel Dekker, Inc. 2001, pp. 1-41. 